Revista Iberoamericana, Vol. LXXVI, Núm. 232-233, Julio-Diciembre 2010, 713-723

\title{
LA TRAGEDIA DEL INMOVILISMO O LA LIBERTAD COMO RESISTENCIA
}

\author{
POR \\ María Dolores Adsuar Fernández \\ Universidad de Murcia
}

El no es el rotundo título que escogió Virgilio Piñera para una de sus obras dramáticas más representativas y delirantes. Fue escrita en el año 1965 y, teniendo en cuenta las indicaciones que propone Rine Leal para la ordenación del Teatro completo de Piñera, ${ }^{1}$ sería una pieza-bisagra en el conjunto de su producción, figurando como la decimocuarta en el corpus completo del teatro piñeriano. Ese lugar cronológico coincidiría con esa misma posición intermediaria en el sentido más profundo de la evolución teatral, tanto desde el plano semántico cuanto desde el estilístico y estrictamente escénico. Creemos, así pues, que esta tragedia de la negación contiene las características más singulares del universo dramático del cubano y que sintetiza el sentido más hondo de su dimensión "teatral".

Desde el prisma de su estructura, la obra se divide en cinco actos más dos microescenas, a modo de prólogo y epílogo. ${ }^{2}$ En su desarrollo transcurren cuarenta años $y$, como es habitual en el teatro de Piñera, el ensanchamiento de la unidad temporal se contrarresta con un respeto estricto a la unidad de espacio. Ya en las acotaciones al Acto Primero, fiel a su escrupulosa descripción de los ambientes a través de esta técnica dramática, Piñera compone un escenario que no variará esencialmente en toda la obra: “Dos sets. El de la izquierda del espectador es una sala: sofá, dos sillones,

1 Fue escrito y fechado por Leal en febrero de 1989. Leal murió en 1996, por lo cual no pudo ver culminada su edición. En su texto, cita el prólogo que Piñera escribiera en 1960 de su entonces Teatro completo para Ediciones R(evolución), y añade: "Virgilio escribe este prólogo en 1960, pero en realidad podemos afirmar que la mayor parte de su escena espera aún hoy, diez años después de su muerte, el reconocimiento público" (Leal xix).

2 Suponemos que a ello se refería Leal cuando señala en su "Prólogo" que la obra tiene "dos prólogos”, aunque los editores del libro lo tomaran por un lapsus e indicaran que la obra "tiene realmente dos finales, y uno de ellos no ha aparecido hasta el momento de la publicación de este libro” (xx). El libro apareció en La Habana en 2002 y no tenemos noticia de una nueva edición de la obra. Sin embargo, la misma editorial Letras Cubanas editó en 1993 un volumen con el Teatro inédito de Virgilio Piñera, que contenía: El no, La niñita querida, Una caja de zapatos vacíos, Nacimiento de palabras y El trac. No obstante, la edición de 2002 incluye como inéditas otras obras que esta edición no compila. 
dos butacas, mesa de centro, espejo con su consola, lámpara de pie. El de la derecha del espectador es un consultorio médico: mesa de trabajo, mesa de curaciones, vitrina con instrumental quirúrgico, silla giratoria, butaca” (Piñera, Teatro completo 378). La insistencia en los espacios es marca habitual del universo piñeriano, en efecto, y subraya la línea dramática que trazamos, y en la que El no ocupa un lugar destacado: Electra Garrigó (1941), Jesús (1948), Aire frío (1959), El no y Dos viejos pánicos (1967). ${ }^{3}$ En todas ellas, la insistencia en un mismo ámbito escénico es fundamental y determina el sentido absoluto de la insistencia y del inmovilismo, paradójicos motores para la concepción existencial del cubano.

Los cuarenta años que ocupa la acción dramática estarán centrados en un argumento que se emparenta con el absurdo en su cualidad desmesurada y en la apuesta por determinaciones existenciales llevadas al extremo, a su límite absoluto donde roza lo imposible y el despropósito. Empero la trama compuesta por Virgilio Piñera cabe ser sometida a otro tipo de consideraciones, tanto de tipo ideológico como filosófico y político. Emilia y Vicente, los protagonistas de la tragedia, serán emblemas de una actitud de negación ante el componente ritual que comporta la representación de determinados papeles sociales. Los conoceremos muy jóvenes en el primer acto, y los veremos permanecer incólumes en su misma resolución al llegar a su vejez. Simbolizan una actitud de resistencia frente a la convención, ya que caracterizan con su "no" el rechazo a convertir su relación de noviazgo en un matrimonio. No hay argumentos externos, presiones familiares ni discusiones fundadas en la razón o en el requiebro desesperado que les hagan variar en su inflexible determinación. Son los actores del "no" absoluto, arraigado y eterno. Nada ni nadie podrá disuadirles. Ni la vida ni la muerte, ni el peso de los patrones familiares ni los enunciados a fortiori. Tampoco el peso del tiempo con sus mutaciones correspondientes los mueve a variar un ápice su postura. Representan la fuerza de la gravedad en la decisión tajante y plena, inmodificable e inexorable, concluyente. Una "poética del no", en la línea de la que acuñó Gaston Bachelard, ${ }^{4}$ como medio paradójico de afirmación y del carácter asertivo, los convierte en nuevas máscaras donde el teatro contemporáneo subvierte los valores del mundo clásico. La hybris del héroe greco-latino surge en esta obra como una fuerza no menos ciega y radical que en su apariencia ateniense, pero adopta ahora la forma del anti-heroísmo, y su contenido es inverso. Los héroes de la antigüedad se valían de su desmesura para contrarrestar las fuerzas ciegas del fatum y conseguir, activando las peripecias

3 Señalamos las fechas de escritura de las obras, según la cronología de Rine Leal, y no la de su publicación ni la de su estreno.

4 En La philosophie du "non" (1940) acuña Bachelard una teoría de la imaginación, donde el espacio de lo representado es más valioso que el de la mirada habitual, donde no llega a "verse" con los ojos de la verdadera creatividad el mundo. Con su filosofía del no, abraza el fenomenólogo francés un ámbito propio a despecho de su renuencia al mero dispositivo racional del género humano.

$\begin{array}{lllll}\text { ISSN 0034-9631 (Impreso) } & \text { ISSN 2154-4794 (Electrónico) }\end{array}$ 
que potencia el giro de los hechos, con su conducta heroica y sacrificada que el orden trastabillado entre los dioses y los hombres vuelva a su armonía.

Frente a ello, las contrafiguras piñerianas desmesuran una decisión que no comporta ningún tipo de reordenación de los niveles existenciales, sino que tiene su fin en sí misma, en su voluntad de perseverar voluntaria y libremente en el acto puro de aserción en la negatividad de cuanto no es identificado como propio. No atienden a ningún tipo de planteamiento ajeno que pueda remover la fuerza de su elección, aunque ésta contenga el desmantelamiento absoluto de la norma e incluso derive en el absurdo y, por ende, en la destrucción del statu quo y del orden instituido social y familiarmente. Con ello sus protagonistas no pretenden remover las estructuras estancas de la sociedad ni revolucionar mecanismos encorsetados por la fuerza de la costumbre. No. Tan sólo son fieles a sí mismos, al margen de todo, e incluso ellos mismos instauran con su tozudez e insistencia superlativas un nuevo orden absurdo para los demás, en el que quisieran pervivir: un cambio que les afecta a su modo de vida y que desembocará en otra fuerza consuetudinaria donde construir su propia morada.

Y así, desde el Acto Primero, los personajes son retratados con suma lucidez en un detalle costumbrista donde queda acrisolado el sello de sus personalidades: Vicente y Emilia aparecerán sentados en sendos sillones y, tras cerrar el libro que está leyendo y comenzar el acto de mecerse, le hace saber Vicente a su "prometida" que los sillones han sido cambiados y que, por tanto, la "fuerza de la costumbre" ha sido infringida, contraviniendo el orden autónomo que ellos imprimen con tenacidad a la existencia. Una vez subsanado el trueque de los sillones, la conversación plantea el conflicto central de lo que será la tragedia de El no. La lectura en el sillón se complementa con el acto de tejer de Emilia, de evidentes resonancias simbólicas y literarias, y ambas acciones son emblema de una operación común. Son actos que se autoabastecen y no que no se plantean como móviles de ulteriores realizaciones, ni tampoco se instauran como la secuencia de una cadena que derive hacia fines ulteriores y externos. Son acciones inmanentes y autosuficientes, y detentan su modo de existencia. Ese modelo es el elegido por estos seres, y a su ejercicio han dedicado ya los primeros cinco años en comunidad de intereses.

Su felicidad se identifica con la ausencia de proyectos que rebasen las cuatro paredes de la sala donde Emilia recibe todas las tardes a Vicente de nueve a once, y en la que ocuparán siempre idénticas posiciones. Su única ambición se concreta en el deseo de cambiar el espacio de su ubicación y pasatiempo a la sala contigua, donde Pedro -el padre de Emilia- ejerce su trabajo como médico de familia. Salvo eso, todo lo demás es accesorio y se muestra ajeno a sus intereses: nada buscan, nada reclaman, nada esperan. Se aman en ese territorio donde la vida late a media voz, donde los días pasan de puntillas y todo el espectáculo inmenso de la realidad se diluye en una nebulosa de indiferencia. Son felices porque nada más precisan ni requieren. Son dichosos porque saben que su promesa de compañía será eterna y fiel, limitada a lo que ya poseen, ausente

\footnotetext{
\begin{tabular}{l} 
Revista Iberoamericana, Vol. LXXVI, Núms. 232-233 Julio-Diciembre 2010, $713-723$ \\
\hline ISSN 0034-9631 (Impreso)
\end{tabular}
} 
de todo estímulo ulterior, de todo proyecto de cambio o modificación. Han extirpado de sus vidas el deseo como motor de acción y acicate de consecuciones ulteriores. Si el deseo es una ausencia que se pretende llenar, ellos no conocen el deseo, pues sus necesidades afectivas y espirituales ya han sido colmadas y, por tanto, sólo les queda perdurar en ellas. Pero perdurar para ellos se convertirá en una forma de resistencia, ya que el nudo dramático aparecerá precisamente por la oposición entre su modus vivendi y el modelo social que la convención del mundo externo impone y, por ende, les exige. Por tal razón, desde su primera conversación nos harán saber que su dicha plena, autosatisfecha y ya realizada, se enfrenta con la norma y habrá de convertirse al fin en una verdadera batalla campal de intereses: los ya satisfechos y dilatados en el tiempo ad infinitum, que ellos ilustran, frente a los que detentan las fuerzas sociales: la familia, los vecinos y el sentir general de la mayoría. Como dijera Sócrates, el sabio puede sonreír ante el espectáculo de las necesidades vacuas que mueven al común de los mortales, y desdeñar todo aquello que no necesita. Pero en el caso de la pareja del “no”, Piñera lleva la resolución socrática hasta el extremo, hasta la máxima dilatación de las fuerzas encontradas y, por tanto, hasta el paroxismo del conflicto, abocándolo a las simas del absurdo y al descontrol de los presupuestos existencialistas. Nos hallamos, pues, frente a unos héroes desmesurados a fuerza de no tener voluntad ni deseo más que el de perseverar en lo que ya han conseguido: una vida que monótonamente se repite a sí misma, descarnada y desapasionada a base de extirpar dimensiones connaturales al ser y consuetudinarias en la historia de ese "animal social" que es el hombre: el paso de un ciclo vital a otro, consagrado por los ritos de paso que implican la modificación del estado. Para Emilia y Vicente no es imprescindible el rito, porque no anhelan ninguna metamorfosis, y ni siquiera el instinto sexual aflora en sus cuerpos, ya que también ha sido extraditado de sus almas. Y dado que el rito es innecesario y aun contrario a su sistema ya establecido de vida feliz, optan continuamente por dar el "no" a otro compromiso que reflejase un cambio de estado civil.

Esta será la "estructura del no" que, a decir de Antón Arrufat, labra el registro temático central de la literatura piñeriana. Recordemos cómo Electra Garrigó, la variante antillana de la "desmesurada” heroína tebana, clamaba en su monólogo ante los "nodioses”, y en su hiperbólica escena final se autoafirmaba, tras la consumación de la muerte de su madre adúltera y del amante que usurpó el lugar del viejo Agamenón, en una puerta de la que ya jamás saldría: la puerta del "no partir”. También el barbero Jesús de Piñera comparece ante sus seguidores negando toda similitud con el Hijo de Dios y, por ende, desestimando su naturaleza mesiánica y salvadora, aun a riesgo de ser perseguido y sacrificado por evitar el parentesco. Decir no es para Piñera un oblicuo modo de afirmación. Afirmarse en el no es tan válido como consolidar una permanente voluntad afirmativa en las solicitudes e invitaciones de la vida. Asimismo René, el protagonista de su novela La carne de René (1952), abomina de todo contacto carnal y niega de manera impetuosa e irrevocable los envites que paradójicamente se

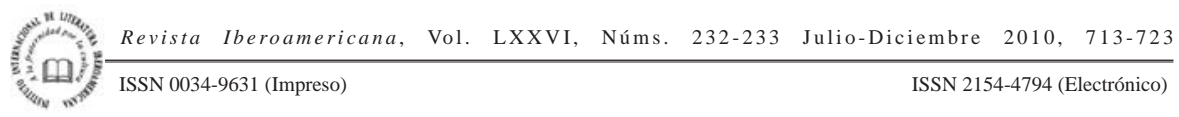


multiplican a medida que se ratifica en su negatividad sustantiva. Todos los personajes que exhiben esta estructura del no terminan construyendo un escenario donde habrán de enfrentarse abiertamente a los contrincantes que fuerzan sus posiciones para rebatir la testarudez de sus posiciones a base de fintas y engaños, o bien recurriendo a la presión y a la violencia. De ahí la entraña dramática del argumento, y por ello es tan válida la dinámica interna de los mismos en su aplicación teatral, centrada en el enfrentamiento como motor de la acción. O, en este caso, de la no-acción, impelida a serlo desde los agentes exógenos.

En este sentido, Emilia y Vicente son dos rostros complementarios de un mismo principio. Fungen como personajes-espejos, y no podrían existir sin su "media naranja” que los justifica y posibilita en el plano de la realidad. Su modelo de relación vendría a corresponderse con el de un "matrimonio de hermanos", de una consistencia abúlica y rutinaria, consistente en repetir las acciones consabidas y abominar de todo trueque o modificación. Recuerdan, en este sentido, a los protagonistas del cuento de Julio Cortázar "Casa tomada", donde hallamos una pareja por el personaje masculino narrador y su hermana Irene: también en este relato las acciones "cliché" identifican a los seres en su absoluta reiteración hecha costumbre férrea: la lectura por parte del sujeto masculino (como Vicente en la obra de Piñera) y el tejido de Irene, también al igual que Emilia. Esta similitud va más allá de lo casual, ya que invade también el tejido de la ficción al postularse el motivo de la "invasión” del territorio. En el cuento de Cortázar, la casa donde moran los hermanos será amenazada por fuerzas extrañas que los desalojarán paulatinamente, y en la pieza dramática de Piñera, la pareja habrá de vérselas primero con los padres de Emilia como emblemas del dictum familiar, y al final con la asociación de vecinos y con las fuerzas del orden jurídico y moral, como símbolos del orden social instituido. En ambos casos, además, la dinámica del "no" será no sólo la "decisión”, sino la fuerza que implemente un modelo vital: los habitantes de la "casa tomada" han renunciado al compromiso con la vida externa y también al amor con otros sujetos. Vicente y Emilia, a su vez, extraen de su original comportamiento la tenacidad de su lucha frente a "los otros". Esos otros que, según definición de la pareja, serán "el resto". Es decir, todo lo sobrante e innecesario: la excrecencia de sus vidas. Por esa razón la acción fetiche de ambas mujeres, Irene y Emilia, no podría ser otra que la de tejer y destejer de manera continua, como Penélopes descreídas y desmitificadas, mujeres que no tienen nada que esperar, pero que fatigan una acción aparentemente productiva, con el fin de evidenciar con ella el paso de un tiempo que no ambiciona ningún regreso y que, por ello, accede a deshacer las mismas prendas que anteriormente fueron creadas.

Conscientes, pues, de su condición de seres "peligrosos" para ese conjunto variopinto y extraño que son "los otros", no les queda otra opción que la de combatir. Un combate que, en su caso, es una resistencia pasiva. La diferencia entre la estrategia

\footnotetext{
Revista Iberoamericana, Vol. LXXVI, Núms. 232-233 Julio-Diciembre 2010, $713-723$
ISSN 0034-9631 (Impreso)
} 
de los contendientes es muy clara para Vicente: sus antagonistas, aunque amparados por el poso de la tradición y la fuerza de la ley, siempre estarán "a la ofensiva”, mientras que su modo de luchar será permanecer incólumes, impasibles y persistentes, situándose siempre "a la defensiva", como si nada sucediese, bien afianzados en la extremo poder de su convicción. Ellos son completamente conscientes de su naturaleza, y no se engañan; Emilia le espeta a Vicente: "Ni tú ni yo somos inocentes". Y él le define con toda propiedad el concepto de vivir al margen de la ley,

\begin{abstract}
pues para estar dentro de ella, hay que empezar por no sentir un amor como el nuestro. Ten siempre presente que en estos sillones fue tomando forma nuestra manera de querernos, la que tú formulaste diciendo: "Nada hay mejor que estar sentados en ellos”. Y ahí empezó todo. [... ] y fueron necesarios cuatro años para llegar al convencimiento absoluto y estar muy conscientes de que no existe otra solución [...]

[...] Y vuelvo a sentarme en mi sillón, y te vuelvo a mirar y todo vuelve a entrar en el orden, es decir, en nuestro orden. (382-383)
\end{abstract}

En esta querella entre los órdenes del mundo y los del "no" a dicho mundo, Emilia y Vicente saben que su mayor fuerza y aliado es precisamente "el tiempo": un tiempo con el que siempre cuentan porque ya están "instalados en él”, porque no tienen nada que esperar ni proyectan ninguna imagen en el futuro. Son, como quería María Zambrano, soberanos de su tiempo, se han "enseñoreado" del mismo, ${ }^{5}$ y han tomado así posesión de una realidad, precisamente por negar la estipulada y no confiar su destino a nada que no sea lo que ya es. Frente a ellos, los antagonistas del drama (en especial Laura y Pedro, progenitores de Emilia) son conscientes de que sus armas no son las que marca el reloj. En una escena paralela a la que se desarrolla entre la pareja de novios y en el momento en que éstos establecen la constitución de su "no" primordial, los padres se refieren a ellos como "muertos en vida" o seres de "sangre de horchata", instalados plenamente en una conciencia consolidada por la costumbre y el principio de la generalidad. Cuando Pedro, más tolerante, le pide a su esposa que dé "tiempo al tiempo", ella le responde de modo cortante: "El tiempo es lo que me horroriza".

Y no le falta razón: en el Segundo Acto de la tragedia han transcurrido cinco años desde su primera escena. Recordemos que ya habían pasado cinco desde que los novios se "prometieran": diez años por tanto en la dinámica de las visitas vespertinas y los sillones silentes, donde el libro y la costura suplantan las caricias y los besos. Diez años y un mismo espacio en el que Vicente y Emilia habrán declarado que sus únicos

5 “El tiempo se hace así vehículo de libertad”, decreta Zambrano, para quienes sostienen que el tiempo no solamente existe externamente, sino que existe "para ellos” (Zambrano 19).

Revista Iberoamericana, Vol. LXXVI, Núms. 232-233 Julio-Diciembre 2010, 713-723
ISSN 2154-4794 (Electrónico) 
hijos serán ellos mismos, perpetuando ese principio de afianzamiento en la decisión inamovible y pertinaz. Piñera recupera así uno de los motivos más frecuentados en su narrativa, cual es el tema de la regresión a la infancia desde la edad adulta. Sin embargo, no se trata ahora tanto de un regreso como de una parálisis. Vicente es el "hijo" de Emilia no ya por el hecho de que regrese al útero para invertir un ciclo vital, sino por su persistente permanencia en un estado de inmovilidad que, a fuerza de no procrear ni fecundar cosa alguna, se postula como su propio y único hijo. El decurso temporal se torna, por lo tanto, inexistente para ellos, por más que sea sangrante y trágico para sus padres. Los años convierten a los novios eternos en seres grotescos y deformes, viejos prematuros, copias decrépitas de una lozana juventud marchitada sin fecundar. Pero la decadencia física no es óbice ni cortapisa para ellos: el tiempo, como sabemos, es su aliado, y los cambios que comporta no afectan a la naturaleza de su decisión esencial, inalterable, renuente a toda variación. Y así, en el Acto Tercero se habrán sucedido diez años más, y hasta veinte desde entonces se contarán cuando nos encontremos con los viejos y eternizados novios en la misma sala, aunque ahora con la novedad de que una pecera habrá reemplazado el altar que Laura dispuso para una ceremonia eternamente postergada. Peces de mirada neutra e inexpresiva que chocan eternamente con la misma pared de cristal, y cuyos nombres no podían ser otros que los de Vicente y Emilia, como mudas réplicas de su “inhumana” existencia.

En cuanto a los cambios producidos en el terreno humano, el espectador habrá asistido a la muerte súbita de Pedro, a consecuencia de un infarto sufrido durante una conversación con Vicente, donde trataba de obligarle a cambiar su "decisión” y en cuyo transcurso no pudo soportar la imperturbabilidad y obstinación de su "yerno". La dialéctica de los dos hombres expone el lado más desgarradoramente absurdo de la pieza, en el sentido cabal y etimológico de un "diálogo de sordos". La batería retórica de argumentos expuestos por Pedro -la voz de la autoridad y del consenso social unánimemente aceptado- choca contra el muro del plúmbeo "no", que se cuela por todos los intersticios argumentativos y saca partido de la pérdida de paciencia del “dictum” canónico. Sortea con habilidad los repuntes del discurso oficial y aúna de modo extraño y sorprendente la sutileza expositiva con la solidez de su posicionamiento. Ante el empaque y la fortaleza de su adversario, la fuerza de la tradición tendrá que resistirse y al fin claudicar, aunque sea feneciendo por desesperación. El grado de exasperación se adueña del personaje adulto que no podrá soportar cómo una postura tan extraña a la razón puede ser tan clarividentemente coordinada. El factor que desencadena su excitación definitiva se precipitará al escuchar cómo la lógica razona sobre la "locura" de la regresión consentida hacia la infancia, que los novios adoptan como modo de expresión "sublime" de sus sentimientos. Y así, como asegurará Laura en el Acto Tercero refiriéndose a Vicente: "hablar con él mata".

También ella será víctima propiciatoria en la tragedia. En el Acto Tercero la veremos urdiendo un plan estratégico a la desesperada con un antiguo amigo de la

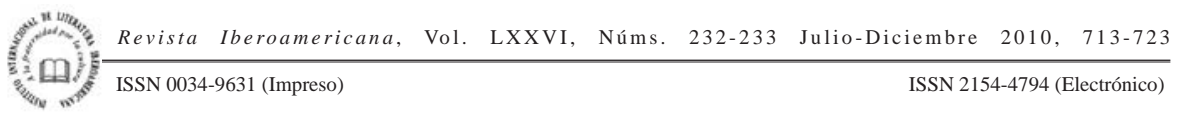


casa cuya hija, en contraste con Emilia, va a contraer matrimonio. La escena ha sido inteligentemente introducida por Piñera hacia la mitad de la pieza como contrapunto a la situación extrema que viven los personajes con la inserción del medio externo, funcionando también como termómetro del "crescendo" en la locura generada en la familia por la fuerza del "no”. Su propósito será inane y fracasará de modo estrepitoso, como tendremos ocasión de comprobar en el Acto Cuarto, en una escena de culminación en el grado de desquiciamiento emocional que padecerá Laura, y que finalmente le nublará la razón hasta el delirio. Dicho momento contendrá una cualidad climática que guarda evidentes puntos de contacto con otras escenas del teatro de Virgilio Piñera, como la del envenenamiento de Clitemnestra Plá con la "frutabomba" por parte de sus hijos Electra y Orestes Garrigó, al comienzo de su itinerario teatral. La escena en que Laura expone a su amigo Ernesto la etopeya de su hija Emilia y su novio Vicente gradúa agudamente la intensidad dramática, y en ella el horror que siente hacia la carne de su carne le lleva a definirla como "la estatua de la impasibilidad", describiendo a la pareja como difuntos en vida que carecen de "ese órgano maravilloso" que late en el común de los mortales y que en ellos ha sido sustituido por el reloj de la rutina apática. Sentimiento que, no obstante, reviste para ellos la naturaleza de un amor compartido, un grado de compenetración absoluta y un espíritu de resistencia capaz de mantenerse incólume ante cualquier acometida. Por tal motivo, el carácter glacial y el dispositivo de "frialdad" que anima el espíritu de la pareja será una fuerza incombustible, y las tácticas y artimañas de Laura se desvanecerán en las nieblas de su progresiva demencia. Como vemos, la locura y la frialdad vuelven a amalgamarse en la literatura piñeriana, como ya sucediera en las colecciones de relatos Cuentos fríos y El que vino a salvarme, donde ya armonizaban en argumentos disonantes y descabalados, pero factibles en el universo de la realidad inventada.

De modo análogo veremos cómo la estructura interna de la frialdad-que anima los calores del "no"- precipita a Laura en la sinrazón, materializada en grotesca bufonada que inventará para consumar el "sí" ante un altar que terminará convirtiéndose en su féretro. Esta escena del Acto Cuarto estampa un largo monólogo de la locura-como remedo del sublime modelo de los personajes femeninos enloquecidos que tanto gustaban a Piñera- que rememora no sólo momentos clásicos de la escena universal, como la locura de Ofelia o la de Lucía de Lammermoor, sino que a su vez exhibe las cualidades de un gran dramaturgo que conoce a la perfección del técnica del monólogo como expresión señera de la caracterización teatral. La mímica que representa el personaje escenifica en el teatro de la imaginación de Laura el rito del matrimonio, pero en realidad las acciones son virtuales carecen de contenido auténtico, lo que produce un efecto de choque en el espectador, así como un realce del sentido absurdo que destila la obra, evocando títulos emblemáticos del teatro contemporáneo europeo como Las sillas de Eugène Ionesco, por el arte de exhibir en ambas obras una serie de acciones en falso utilizando el mobiliario de modo repetitivo, mecánico e inane. En realidad,

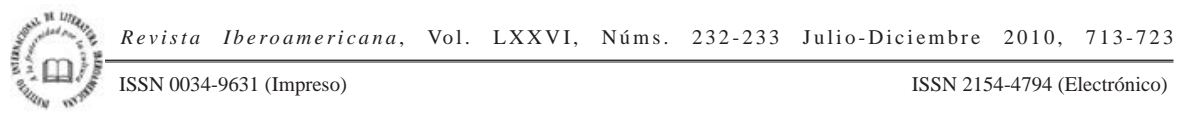


Vicente y Emilia ya han ritualizado la ceremonia del "no" en un acto que supondrá la réplica en negativo del momento en que los contrayentes de una boda se dan "el sí". Los rotundos "noes" resuenan entonces como martillos en la conciencia perturbada de Laura, que ha querido fungir como sacerdotisa en una farsa descomunal.

Este momento álgido de la tragedia tendrá una conclusión en el Acto Quinto, en que hallaremos, tras la defunción de los padres de Emilia, a los actores sociales que representan un proceso en contra de los ya decrépitos novios, y donde aparecerán nuevos personajes que, con renovadas e insistentes disquisiciones, removerán la historia para persuadir a los protagonistas de su culpabilidad en el desenlace fatal de los hechos. Mas todo será en vano, pues -aun acosados por el medio y acorralados en lo más recóndito del espacio y de la conciencia- Vicente y Emilia no renegarán de su decisión existencial, de su tajante poética mortal del inconmovible "no". La solución del suicidio se encenderá como un estallido probable, aunque no materializado, que les confirme hasta el final en la postura defendida a ultranza y llevada hasta el límite de lo imaginable, aproximado a la condición del martirio como reafirmación en un principio... aunque esa "afirmación” sea contradictoriamente la afirmación de un no infinito y eterno.

Y así, entre lo ridículo y lo sublime oscila el péndulo emocional que invade al lector y al espectador del "no". Suplantando así al horror y a la compasión, la catarsis se desencadena ahora entre esos dos extremos de la fabulación (lo excelso y lo grotesco), pues los personajes de El no son los héroes de una anti-heroicidad absoluta. Unos héroes que prefieren morir abrazados como niños antes que dar su brazo a torcer en aras de un imposible altar. La obra adquiere entonces una cualidad dramática que la acerca a los postulados de "teatro épico" de Bertolt Brecht y, dentro de su extensa producción, sobre todo a su obra más dual: El que dijo sí y el que dijo no, texto que, sin duda, tuvo presente Piñera a la hora de diseñar su fábula. La de unos anti-héroes trágicos que matan y aun mueren en su empeño por "decir no”. La técnica piñerariana es deudora asimismo de las fórmulas brechtianas del distanciamiento dramático. Sucede algo similar a lo que acontece con los personajes en El que dijo sí y el que dijo no, que repiten en el segundo acto de la pieza de manera idéntica los parlamentos y las acciones que ya realizaron en el primero, hasta llegar al punto crítico donde deben modular su decisión y esgrimir la respuesta negativa ante el interrogante abierto por la tradición. En la obra de Piñera, la pareja protagonista podrá ser valorada de manera polar y antagónica según se juzgue su caso desde unos parámetros u otros. Este ejercicio de relativismo adopta, en efecto, la dinámica brechtiana, y en el Prólogo escénico de El no un Narrador y un Interruptor se habrán dirigido a los espectadores para presentar a las figuras desde planos dicotómicos: como monstruos sin entrañas o como "dos seres humanos”. El veredicto queda así suspendido a juicio del público, liberado ante ese “yo plural" que con sus mil cabezas podrá decretar de modo diverso la naturaleza de los hechos presentados. Como vemos es un procedimiento de raigambre épica muy bien

\footnotetext{
Revista Iberoamericana, Vol. LXXVI, Núms. 232-233 Julio-Diciembre 2010, 713-723
ISSN 0034-9631 (Impreso)
} 
atraído por el cubano en esta pieza tan “distanciada”, y que en España sería asimismo utilizado por dramaturgos como Antonio Buero Vallejo en sus obra El tragaluz o La doble historia del doctor Valmy. En todos los casos hallamos la misma constancia y evidencia de hallarnos ante el teatro en estado puro.

¿Monstruos o seres humanos que defienden el derecho a una vida libremente elegida? La tragedia del inmovilismo tendrá como agentes a dos individuos que reclaman su libertad y que utilizan para ello todos los estiletes de la resistencia. Un modo de resistir en modelos de frialdad o de locura, de absurdo o de desentrañamiento: no importa. El hecho es que Vicente y Emilia testimonian el espectáculo tragicómico elevado a la enésima potencia de su obstinación en la "poética del no". Nos pueden resultar incomprensibles en su desencarnada satisfacción y su loa lírica del "beato sillón” podrá aparecer como expresión ridícula de un paraíso de salón ya encontrado en la tierra, pero en todo caso estas criaturas de ficción son la carne y el alma de una posición consciente, asumida y arraigada, y de algún modo defendible por su asomo de convincente verdad. No en vano Rine Leal publicó unas notas del legado dramático de Piñera, conservado en la colección de la Biblioteca Nacional José Martí en La Habana, donde éste había estampado en una hoja mitad manuscrita y mitad mecanografiada la esencia ambigua, esquiva y tortuosamente teatral que sustentaba la arquitectura psíquica e ideológica de El no: "Fondo anecdótico. Teoría de la situación límite. El derecho a decir No. Consecuencias y deudas con el medio social” (Leal xxiii).

Derecho a decir No. Una gran conquista para los protagonistas de ese medio social en el que vivió Virgilio Piñera, y también de todo medio social donde el hombre, por costumbre y naturaleza, ha de vivir y de sobrevivir.

Un derecho que convierte a sus actores en los conquistadores de una hazaña absurda pero tal vez necesaria, en la que morirán inocentes y "no inocentes", y en la que sus protagonistas también habrán de sucumbir al cabo. Bien por el estallido de una bombona de gas, o bien convertidos en los grotescos enemigos de sí mismos que repetirán como “dos viejos pánicos” en una condena eterna sus propios círculos de frialdad.

Revista Iberoamericana, Vol. LXXVI, Núms. 232-233 Julio-Diciembre 2010, $713-723$
ISSN 0034-9631 (Impreso) 
BiBLIOGRAFÍA

Arrufat, Antón: "Virgilio Piñera y la estructura de la negación”. Unión 19 (La Habana, Abril-Junio, 1995): 54-59.

Bachelard, Gaston: "La philosophie du non”. Paris: Presses Universitaires, 1940.

Brecht, Bertolt. El que dijo sí. El que dijo no. Teatro completo. Vol IX. Buenos Aires: Nueva Visión, 1966.

Leal, Rine: "Prólogo" a Virgilio Piñera: Teatro completo. La Habana: Letras Cubanas, 2002. v-xxxiii.

Piñera, Vigilio: Teatro completo. La Habana: Letras Cubanas, 2002. Compilación, ordenamiento y prólogo de Rine Leal.

Teatro inédito. La Habana: Letras Cubanas, 1993.

Zambrano, María. Los sueños y el tiempo. Madrid: Siruela, 1992.

Revista Iberoamericana, Vol. LXXVI, Núms. 232-233 Julio-Diciembre 2010, 713-723 ISSN 0034-9631 (Impreso) ISSN 2154-4794 (Electrónico) 
